\title{
Giulia Oskian, Machiavelli, Montaigne, Charron: modelli antropologici e sviluppi politici
}

\section{Filippo Fassina}

\section{Q OpenEdition}

1 Journals

\section{Edizione digitale}

URL: http://journals.openedition.org/studifrancesi/9849

DOI: 10.4000/studifrancesi.9849

ISSN: 2421-5856

\section{Editore}

Rosenberg \& Sellier

\section{Edizione cartacea}

Data di pubblicazione: 1 octobre 2007

Paginazione: 431

ISSN: 0039-2944

\section{Notizia bibliografica digitale}

Filippo Fassina, «Giulia Oskian, Machiavelli, Montaigne, Charron: modelli antropologici e sviluppi politici», Studi Francesi [Online], 152 (LI | II) | 2007, online dal 30 novembre 2015, consultato il 08 janvier 2021. URL: http://journals.openedition.org/studifrancesi/9849; DOI: https://doi.org/10.4000/studifrancesi. 9849

Questo documento è stato generato automaticamente il 8 janvier 2021.

\section{(c) 9 (i) $\Theta$}

Studi Francesi è distribuita con Licenza Creative Commons Attribuzione - Non commerciale - Non opere derivate 4.0 Internazionale. 


\title{
Giulia Oskian, Machiavelli, Montaigne, Charron: modelli antropologicie sviluppi politici
}

\author{
Filippo Fassina
}

\section{NOTIZIA}

GIULIA OSKIAN, Machiavelli, Montaigne, Charron: modelli antropologici e sviluppi politici, «Rinascimento», XLIV (2004), pp. 251-272.

1 L'autrice propone un confronto tematico tra le opere di Machiavelli (soprattutto i Ghiribizzi, ma anche il Principe e i Discorsi) e il primo degli Essais di Montaigne, confronto esteso anche a Pierre Charron (De la sagesse). La questione presa in esame è essenzialmente «quali fattori determinino il conseguimento di uno scopo». La risposta che fornisce Machiavelli è che l'uomo è inequivocabilmente condizionato dal tempo e dalla propria indole, che non possono essere in alcun modo controllati. La studiosa sottolinea il capovolgimento che Machiavelli opera nei confronti della digni- tas hominis di Pico della Mirandola, in favore della fortuna, nei confronti della quale nessun saggio consiglio può essere utile. Si genera così un paradosso all'interno del pensiero machiavelliano che l'A. identifica nel contrasto tra disincanto e progettualità. La prospettiva di Montaigne è invece definita "estetica», poiché le azioni umane sono così varie da risultare quasi uno spettacolo e tale varietà e incoerenza si riscontra anche nella storia, dalla quale - in dichiarata opposizione a Machiavelli - è pressoché impossibile trarre un insegnamento e a causa di questa inconstance umana, nemmeno gli autori antichi possono fungere da modello. Charron, erede dello scetticismo di Montaigne, si pone dal punto di vista dell'uomo di stato che deve conoscere prima di tutto sé stesso e poi le passioni mutevoli del popolo che deve governare, esercitando una versatile prudenza. Mentre Machiavelli cerca, pur con delle contraddizioni, di 
ricavare regole generali, Montaigne e Charron negano la possibilità di una scienza in favore di un'«antropologia fluttuante» di matrice decisionista. 